medRxiv preprint doi: https://doi.org/10.1101/2022.01.29.22270093; this version posted February 7, 2022. The copyright holder for this preprint (which was not certified by peer review) is the author/funder, who has granted medRxiv a license to display the preprint in perpetuity.

It is made available under a CC-BY-NC-ND 4.0 International license .

\title{
Presentation collateral patterns and outcomes after endovascular thrombectomy for large vessel occlusion stroke
}

Robert W Regenhardt ${ }^{\mathrm{a}, \mathrm{b}}$, Michael $\mathrm{H}$ Lev $^{\mathrm{c}}$, Julian $\mathrm{He}^{\mathrm{c}}$, Adam A Dmytriw ${ }^{\mathrm{a}, \mathrm{c}}$, Justin E Vranic ${ }^{\mathrm{a}, \mathrm{c}}$, James D Rabinov $^{\mathrm{a}, \mathrm{c}}$, Christopher J Stapleton ${ }^{\mathrm{a}}$, Aman B Patel ${ }^{\mathrm{a}}$, Aneesh B Singhal ${ }^{\mathrm{b}}$, R Gilberto Gonzalez ${ }^{\mathrm{c}, \mathrm{d}, \mathrm{e}, *}$

${ }^{a}$ Department of Neurosurgery, Massachusetts General Hospital, Harvard Medical School

${ }^{b}$ Department of Neurology, Massachusetts General Hospital, Harvard Medical School

${ }^{c}$ Department of Radiology, Massachusetts General Hospital, Harvard Medical School

${ }^{\mathrm{d}}$ Athinoula A Martinos Center for Biomedical Imaging

${ }^{\text {e }}$ Mass General Brigham Center for Clinical Data Science

*Corresponding author

55 Fruit Street, GRB 273A, Boston, MA

rggonzalez@mgh.harvard.edu

617-726-8628

\begin{abstract}
:
Background: Endovascular thrombectomy (EVT) revolutionized large vessel occlusion (LVO) stroke. However, treatment decisions and prognostication are challenging without advanced imaging. We sought to determine the relationship of simple CTA collateral patterns and outcomes after EVT.
\end{abstract}

Methods: We identified patients with anterior LVO who underwent guideline based EVT from a single center from 2019-2020. Inclusion criteria were available CTA and 90-day modified Rankin Scale (mRS). Arterial-phase CTA collaterals were categorized as malignant, other, or symmetric.

Results: Among 74 patients, the median age was 75 and $49 \%$ were female. Collaterals were symmetric (36\%), malignant (24\%), or other (39\%). Comparing collateral patterns there were no differences in demographics, presentations, time from last well, good reperfusion, or intracerebral hemorrhage. Median NIHSS was 18 for malignant, 19 for other, and 11 for symmetric $(p=0.02)$. Intracranial ICA occlusions were present in $28 \%$ of malignant, $3 \%$ of other, and $11 \%$ of symmetric $(p=0.04)$. Ninety-day mRS $\leq 2$ was achieved in $17 \%$ of malignant, $38 \%$ of other, and $67 \%$ of symmetric. Collateral pattern was a significant determinant of 90 -day $\mathrm{mRS} \leq 2(\mathrm{aOR}=6.62,95 \% \mathrm{Cl}=2.24,19.53 ; \mathrm{p}=0.001)$ in a multivariable model including age, NIHSS, baseline mRS, thrombolysis, LVO location, and good reperfusion.

Conclusions: Simple CTA collateral pattern is a robust determinant of 90-day outcomes after EVT. Further prospective studies are needed to understand how collateral pattern can guide EVT treatment decisions and long-term prognosis. 
medRxiv preprint doi: https://doi.org/10.1101/2022.01.29.22270093; this version posted February 7, 2022. The copyright holder for this preprint (which was not certified by peer review) is the author/funder, who has granted medRxiv a license to display the preprint in perpetuity.

It is made available under a CC-BY-NC-ND 4.0 International license .

\section{Introduction:}

Large vessel occlusion (LVO) stroke accounts for the largest proportion of stroke-related death and disability. ${ }^{1}$ Acute care for patients with LVO stroke has been revolutionized by endovascular thrombectomy (EVT). ${ }^{2-4}$ However, treatment selection and prognostication can be challenging when advanced imaging, such as CT perfusion (CTP) or MRI, is unavailable. ${ }^{5}$ Unfortunately, community hospitals and underserved regions are often without these resources. ${ }^{6,7}$ This is especially true for patients in the extended window or with unknown onset. ${ }^{8}$ Furthermore, the transfer of patients to thrombectomy capable centers can be delayed, which reduces the likelihood of EVT. ${ }^{9}$

Collaterals are alternative vessels, consisting of primary circle of Willis and secondary pial-pial leptomeningeal anastomoses, that can compensate for reduced blood flow in the setting of LVO. ${ }^{1}$ Collateral patterns vary dramatically among patients with stroke and are highly related to infarct growth. ${ }^{10}$ Indeed, the collateral pattern assessed by presentation CT angiography (CTA) may be an appropriate proxy for infarct volume and infarct growth rate. ${ }^{11}$ In patients with LVO not treated with reperfusion therapies, symmetric collateral pattern on CTA had a sensitivity of $87 \%$ and a specificity of $94 \%$ for 24 -hour infarct volume $<50 \mathrm{cc}{ }^{12}$ We sought to determine the relationship of presentation simple CTA collateral patterns and outcomes after EVT.

\section{Results:}

Among 74 patients who met inclusion criteria from 2019 to 2020, the median age was 75 (IQR 58-82), and $49 \%$ were female. Collaterals were symmetric (36\%), malignant $(24 \%)$, or other (39\%). Comparing collateral patterns there were no differences in demographics, risk factors, time from last known well, thrombolysis treatment, $\mathrm{TICl} 2 \mathrm{~b}-3$ reperfusion, or sICH. Median NIHSS was 18 (IQR 14-23) for malignant, 19 (IQR 12-22) for other, and 11 (IQR 8-18) for symmetric ( $p=0.02)$. Intracranial ICA occlusions were present in $28 \%$ of malignant, $3 \%$ of other, and $11 \%$ of symmetric $(p=0.04)$ (Table 1$)$.

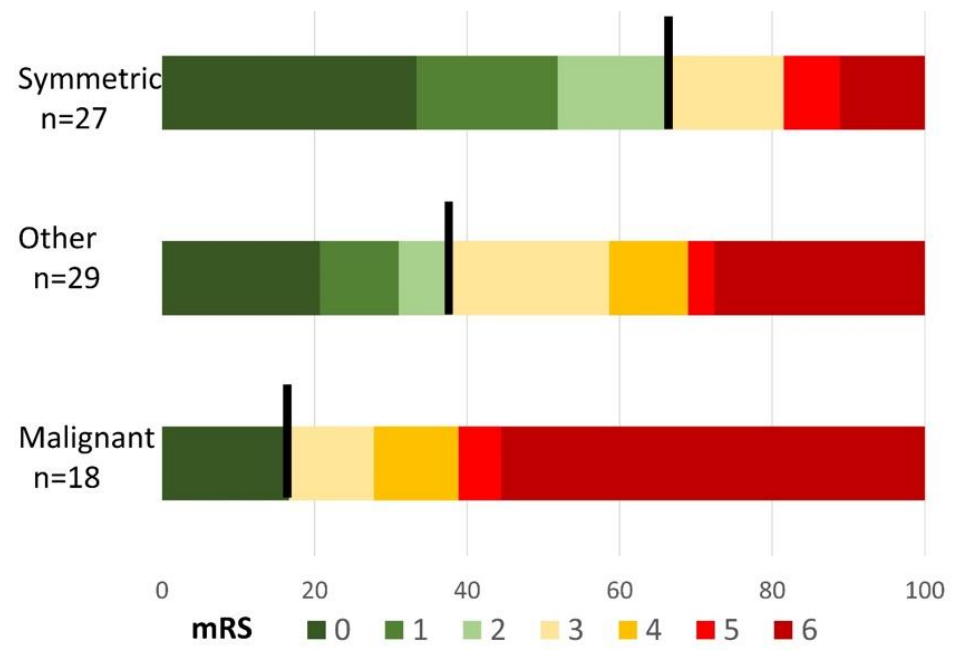

Figure 1. Ninety-day modified Rankin Scale (mRS) score comparing collateral patterns.

Ninety-day mRS $\leq 2$ was achieved in $17 \%$ of malignant, $38 \%$ of other, and $67 \%$ of symmetric $(p=0.003)$ (Table 1, Figure 1). Collateral pattern was a significant determinant of 90-day $m R S \leq 2$ (aOR=6.62, $95 \% \mathrm{Cl}=2.24,19.53 ; \mathrm{p}=0.001)$ in a multivariable model including age $(\mathrm{aOR}=0.92,95 \% \mathrm{Cl}=0.87,0.97 ; \mathrm{p}=0.001)$, NIHSS (aOR=0.98, 95\%Cl=0.89,1.08; $p=0.68)$, baseline $m R S ~ \geq 3$ (aOR=6.14, 95\% Cl=0.60,63.12; $\mathrm{p}=0.13$ ), intravenous thrombolysis $(\mathrm{aOR}=2.14,95 \% \mathrm{Cl}=0.52,8.91 ; \mathrm{p}=0.29)$, occlusion location ( $\mathrm{aOR}=0.53$, $95 \% \mathrm{Cl}=0.16,1.82 ; \mathrm{p}=0.31$ ), and $\mathrm{TICl} 2 \mathrm{~b}-3$ reperfusion ( $\mathrm{OOR}=10.45,95 \% \mathrm{Cl}=1.05,104.3 ; \mathrm{p}=0.05)$ (Table 2 ). 
medRxiv preprint doi: https://doi.org/10.1101/2022.01.29.22270093; this version posted February 7, 2022. The copyright holder for this preprint (which was not certified by peer review) is the author/funder, who has granted medRxiv a license to display the preprint in perpetuity. It is made available under a CC-BY-NC-ND 4.0 International license.

Table 1. Patient demographics, risk factors, presentations, treatments, and outcomes.

\begin{tabular}{|c|c|c|c|c|c|}
\hline & Total & Malignant & Other & Symmetric & P-Value \\
\hline Age, Median (IQR) & $75(58,82)$ & $71(52,82)$ & $76(59,81)$ & $72(59,81)$ & 0.72 \\
\hline Female & 36 (49\%) & 7 (39\%) & $16(55 \%)$ & $13(48 \%)$ & 0.55 \\
\hline Black & $4(5 \%)$ & 2 (11\%) & $1(3 \%)$ & $1(4 \%)$ & 0.47 \\
\hline White & $49(66 \%)$ & $11(61 \%)$ & $16(55 \%)$ & $22(82 \%)$ & 0.10 \\
\hline Asian & $5(7 \%)$ & $1(6 \%)$ & $3(10 \%)$ & $1(4 \%)$ & 0.60 \\
\hline Hispanic & $3(4 \%)$ & $1(6 \%)$ & $1(3 \%)$ & $1(4 \%)$ & 0.93 \\
\hline Baseline $\mathrm{mRS} \geq 3$ & $5(7 \%)$ & $2(11 \%)$ & $2(7 \%)$ & $1(4 \%)$ & 0.62 \\
\hline Atrial Fibrillation & $21(28 \%)$ & $5(28 \%)$ & $8(28 \%)$ & $8(30 \%)$ & 0.98 \\
\hline Coronary Disease & $23(31 \%)$ & 7 (39\%) & $11(38 \%)$ & $5(19 \%)$ & 0.21 \\
\hline Diabetes Mellitus & $19(26 \%)$ & $3(17 \%)$ & 9 (31\%) & $7(26 \%)$ & 0.55 \\
\hline Dyslipidemia & $30(41 \%)$ & $6(33 \%)$ & $11(38 \%)$ & $13(48 \%)$ & 0.57 \\
\hline Heart Failure & $14(19 \%)$ & $4(22 \%)$ & 7 (24\%) & $3(11 \%)$ & 0.42 \\
\hline Hypertension & $52(70 \%)$ & $13(72 \%)$ & $18(62 \%)$ & $21(78 \%)$ & 0.43 \\
\hline Obesity/Overweight & $31(42 \%)$ & $6(33 \%)$ & $14(48 \%)$ & $11(41 \%)$ & 0.59 \\
\hline Previous Stroke & $11(15 \%)$ & $3(17 \%)$ & $2(7 \%)$ & $6(22 \%)$ & 0.27 \\
\hline $\begin{array}{l}\text { Previous TIA } \\
\text { Chronic Renal }\end{array}$ & $4(5 \%)$ & $1(6 \%)$ & $1(3 \%)$ & $2(7 \%)$ & 0.81 \\
\hline Insufficiency & $9(12 \%)$ & $2(11 \%)$ & $3(10 \%)$ & $4(15 \%)$ & 0.87 \\
\hline Smoker & $9(12 \%)$ & $1(6 \%)$ & $6(21 \%)$ & $2(7 \%)$ & 0.19 \\
\hline $\begin{array}{l}\text { Cardioembolism } \\
\text { Large Artery }\end{array}$ & $42(57 \%)$ & $9(50 \%)$ & $18(62 \%)$ & $15(56 \%)$ & 0.71 \\
\hline Atherosclerosis & $10(14 \%)$ & $3(17 \%)$ & $2(7 \%)$ & $5(19 \%)$ & 0.40 \\
\hline Cryptogenic & $14(19 \%)$ & $3(17 \%)$ & $4(14 \%)$ & $7(26 \%)$ & 0.49 \\
\hline Dissection & $2(3 \%)$ & 2 (11\%) & $0(0 \%)$ & $0(0 \%)$ & 0.04 \\
\hline Hypercoagulability & $6(8 \%)$ & $1(6 \%)$ & $5(17 \%)$ & $0(0 \%)$ & 0.06 \\
\hline $\begin{array}{l}\text { NIHSS, Median (IQR) } \\
\text { Intravenous }\end{array}$ & $17(10,22)$ & $18(14,23)$ & $19(12,22)$ & $11(8,18)$ & 0.02 \\
\hline Thrombolysis & $21(28 \%)$ & $6(33 \%)$ & $11(38 \%)$ & $4(15 \%)$ & 0.14 \\
\hline Telestroke Consult & 35 (47\%) & $6(33 \%)$ & $12(41 \%)$ & $17(63 \%)$ & 0.11 \\
\hline Transfer & $43(58 \%)$ & $8(44 \%)$ & $15(52 \%)$ & $20(74 \%)$ & 0.10 \\
\hline LKW-Telestroke & $1.73(1.10,4.17)$ & $1.38(0.99,1.73)$ & $1.53(1.10,3.25)$ & $3.27(1.23,6.00)$ & 0.18 \\
\hline LKW-Hub Arrival & $3.08(0.90,5.07)$ & $2.59(1.81,3.25)$ & $2.63(0.67,4.72)$ & $4.47(2.24,6.68)$ & 0.14 \\
\hline $\begin{array}{l}\text { LKW-Arterial Puncture } \\
\text { Intracranial ICA }\end{array}$ & $3.60(2.70,6.07)$ & $3.42(2.82,4.22)$ & $3.03(2.22,5.37)$ & $5.25(2.72,7.79)$ & 0.16 \\
\hline Occlusion & $9(12 \%)$ & $5(28 \%)$ & $1(3 \%)$ & $3(11 \%)$ & 0.04 \\
\hline M1 MCA Occlusion & $51(69 \%)$ & $13(72 \%)$ & $23(79 \%)$ & $15(56 \%)$ & 0.15 \\
\hline M2 MCA Occlusion & $14(19 \%)$ & $0(0 \%)$ & $5(17 \%)$ & $9(33 \%)$ & 0.02 \\
\hline Stent Retriever EVT & $26(37 \%)$ & $8(44 \%)$ & $10(39 \%)$ & $8(31 \%)$ & 0.64 \\
\hline Aspiration Only EVT & $44(63 \%)$ & $10(56 \%)$ & $16(62 \%)$ & $18(69 \%)$ & 0.64 \\
\hline $\mathrm{TICl} 2 \mathrm{~b}-3$ & $65(88 \%)$ & $15(83 \%)$ & $26(90 \%)$ & $24(89 \%)$ & 0.80 \\
\hline $\mathrm{sICH}$ & $5(7 \%)$ & $3(17 \%)$ & $1(3 \%)$ & $1(4 \%)$ & 0.16 \\
\hline Discharge $\mathrm{mRS} \leq 2$ & $13(18 \%)$ & $1(6 \%)$ & $3(10 \%)$ & $9(33 \%)$ & 0.02 \\
\hline 90-Day $\mathrm{mRS} \leq 2$ & 32 (43\%) & $3(17 \%)$ & $11(38 \%)$ & $18(67 \%)$ & 0.003 \\
\hline
\end{tabular}

Abbreviations: IQR Interquartile Range, mRS modified Rankin Scale, TIA Transient Ischemic Attack, NIHSS National Institutes of Health Stroke Scale, LKW Last Known Well, ICA Internal Carotid Artery, MCA Middle 
medRxiv preprint doi: https://doi.org/10.1101/2022.01.29.22270093; this version posted February 7, 2022. The copyright holder for this preprint (which was not certified by peer review) is the author/funder, who has granted medRxiv a license to display the preprint in perpetuity.

It is made available under a CC-BY-NC-ND 4.0 International license .

Cerebral Artery, EVT Endovascular Thrombectomy, TICI Thrombolysis in Cerebral Infarction, sICH symptomatic Intracerebral Hemorrhage.

Table 2. Determinants of 90-day modified Rankin Scale (mRS) score $\leq \mathbf{2}$.

$\begin{array}{lcccc} & \text { Univariable OR }(95 \% \mathrm{Cl}) & \text { P-Value } & \text { Multivariable aOR }(95 \% \mathrm{Cl}) & \text { P-Value } \\ \text { Collaterals } & 3.19(1.57,6.47) & 0.001 & 6.62(2.24,19.53) & 0.001 \\ \text { Age } & 0.96(0.93,0.99) & 0.007 & 0.92(0.87,0.97) & 0.001 \\ \text { NIHSS } & 0.97(0.90,1.04) & 0.36 & 0.98(0.89,1.08) & 0.68 \\ \text { Baseline mRS } \geq 3 & 0.87(0.14,5.52) & 0.88 & 6.14(0.60,63.12) & 0.13 \\ \text { Intravenous } & & & & \\ \text { Thrombolysis } & 0.74(0.27,2.09) & 0.58 & 2.14(0.52,8.91) & 0.29 \\ \text { Occlusion Location } & 0.97(0.42,2.23) & 0.95 & 0.53(0.16,1.82) & 0.31 \\ \text { TICl 2b-3 } & 3.00(0.58,15.55) & 0.19 & 10.45(1.05,104.3) & 0.05\end{array}$

Abbreviations: NIHSS National Institutes of Health Stroke Scale, TICI Thrombolysis in Cerebral Infarction, OR Odds Ratio, $\mathrm{Cl}$ Confidence Interval.

\section{Discussion:}

In this retrospective analysis of patients who underwent EVT, there was significant variability in collateral patterns, with only $36 \%$ being symmetric. Symmetric collaterals were associated with less severe stroke presentation and good 90-day functional outcome. Even when controlling for age, stroke severity, baseline disability, thrombolysis treatment, occlusion location, and adequate reperfusion, collateral pattern was a significant determinant of 90-day outcome.

Among patients treated with EVT, we noted significant variability in collateral patterns. They were symmetric in $36 \%$, malignant in $24 \%$, and other in $39 \%$. This is consistent with our local EVT treatment selection guidelines, which do not exclude patients based on collateral patterns. Indeed, others have reported a range of collateral quality, albeit assessed differently, among patients treated with EVT. ${ }^{13,14}$ In addition, there was a trend for malignant patterns to have shorter times from LKW, but this difference did not reach statistical significance. This may be related to our treatment exclusion of patients with poor ASPECTS or large infarcts since patients with poor collaterals have faster infarct growth. ${ }^{12}$ Furthermore, more proximal occlusion locations were more likely to have poor collaterals; ICA occlusions were present in $28 \%$ of malignant, $3 \%$ of other, and $11 \%$ of symmetric. This stands to reason, and early studies have explored the relationship between occlusion location and collateral quality. ${ }^{15}$

While there have been some prior analyses of the relationship of collaterals with stroke severity and 90day outcomes, the data are mixed. Furthermore, we contend our assessment of collateral patterns has significant advantages compared to other approaches. ${ }^{12}$ Among our cohort, the median NIHSS was 18 for malignant patterns, 19 for other, and 11 for symmetric. Other studies corroborate our results, showing that patients with poor collaterals have higher NIHSS. ${ }^{11,16}$ Furthermore, 90-day mRS $\leq 2$ was achieved in $17 \%$ of malignant, $38 \%$ of other, and $67 \%$ of symmetric within our cohort. This relationship persisted even when controlling for age, stroke severity, baseline disability, thrombolysis, occlusion location, and adequate reperfusion. There is mixed prior literature regarding this relationship, highlighting the need for further research. ${ }^{11,16,17}$

The mechanism of the relationship between collaterals and clinical outcomes may be explained by presentation infarct volume and infarct growth. Indeed, infarct volume is one of the strongest determinants of 90-day outcomes, even among patients who undergo EVT. ${ }^{18}$ In our prior study, worse collaterals were an independent determinant of both greater presentation infarct volume and infarct growth rate, even when controlling for other variables including occlusion site, NIHSS, and age. ${ }^{12}$ Beyond presentation, continued infarct growth may be important for outcomes even among those who achieve successful reperfusion with EVT. ${ }^{19,20}$ We previously demonstrated that collateral patterns continue to 
medRxiv preprint doi: https://doi.org/10.1101/2022.01.29.22270093; this version posted February 7, 2022. The copyright holder for this preprint (which was not certified by peer review) is the author/funder, who has granted medRxiv a license to display the preprint in perpetuity.

It is made available under a CC-BY-NC-ND 4.0 International license .

affect infarct growth up to 48 hours in patients not treated with EVT, suggesting there is no "collapse" of collaterals over this time. ${ }^{21}$

Importantly, there are several implications from this study. Our classification approach for collaterals has been previously described, ${ }^{12}$ and is consistent with other studies using a three-category approach. ${ }^{22}$ While CTP can be used to estimate collaterals, ${ }^{10,22}$ CTA is more widely available, has no threshold dependence, and allows direct visualization of the cerebral vessels. Our simple classification system is robust and immediately translatable. There is growing data that extended window EVT is beneficial even without advanced imaging. ${ }^{23} \mathrm{~A}$ simple non-contrast $\mathrm{CT}$ and single arterial phase CTA may be sufficient to triage most patients for EVT. Understanding collaterals may also aid in decision making for the inter-hospital transfer of patients to EVT-capable centers. ${ }^{24,25}$ At many smaller hospitals, MRI or CTP are not readily available..$^{6,26}$

There are several limitations to consider. First, patients were identified, and collateral patterns were evaluated retrospectively. There may be some selection bias for patients treated with endovascular thrombectomy. Second, the single center design could limit generalizability. Third, the "other" collateral pattern category was heterogenous, with some patients rated as closer to symmetric and others rated as closer to malignant. Despite these potential limitations, this simple three-category classification system is easy to learn, easy to use, robust, and immediately translatable.

In conclusion, collateral pattern is a robust determinant of 90-day outcomes after thrombectomy. Further prospective studies are needed to evaluate the role collateral pattern in EVT treatment decisions and prognostication.

\section{Methods:}

This study was approved by the local institutional review board. Informed consent was waived based on minimal patient risk and practical inability to perform the study without the waiver. Patients who underwent EVT for anterior circulation LVO were identified retrospectively from a prospectively maintained database at a single referral center. ${ }^{27}$ Inclusion criteria were available CTA for retrospective review and prospectively recorded 90-day modified Rankin Scale (mRS) score.

CTA was performed using multi-detector scanners (GE Medical Systems) from the vertex to the aortic arch following injection of 65-140 ml of a nonionic contrast agent (Isovue; Bracco Diagnostics) at a rate of 3 to $4 \mathrm{ml} / \mathrm{s}$. The median parameters were $1.25-\mathrm{mm}$ slice thickness, $220 \mathrm{~mm}$ reconstruction diameter, $120 \mathrm{kV}$, and $657 \mathrm{~mA}$. CTDI ${ }_{\text {vol }}$ ranged from 65-95 mGY, and DLP ranged from 2593-3784 mGY-cm.

Collateral patterns were interpreted by CAQ-certified neuroradiologists with over 25 years' experience interpreting acute stroke studies (RGG, MHL).Interpreters were blinded to clinical presentations, treatments, other imaging, and clinical outcomes. Patterns were determined by visual review of the maximum intensity projection arterial phase CTA images, which were classified as "symmetric", "malignant", or "other". ${ }^{12}$ Briefly, a symmetric pattern was defined as contrast visualized with similar or near similar conspicuity of the ischemic compared to the contralateral non-ischemic MCA territory. A malignant pattern was defined as no contrast visualized over at least $50 \%$ of the MCA territory at risk. "Other" was defined as any additional pattern, rated as intermediate between symmetric and malignant. Vessel occlusion site on CTA was documented as internal carotid artery (ICA) terminus, first (M1) middle cerebral artery (MCA) segment, and second (M2) MCA segment. ${ }^{28}$ Cervical ICA stenosis was defined as $>70 \%$ by NASCET criteria. ${ }^{29}$

The local database included demographic information, medical history, clinical presentation, treatments, and outcomes for consecutive patients treated with EVT. Stroke severity (National Institutes of Health Stroke Scale, NIHSS) was determined as described. ${ }^{30}$ Alteplase treatment decisions were guideline-based 
medRxiv preprint doi: https://doi.org/10.1101/2022.01.29.22270093; this version posted February 7, 2022. The copyright holder for this preprint (which was not certified by peer review) is the author/funder, who has granted medRxiv a license to display the preprint in perpetuity.

It is made available under a CC-BY-NC-ND 4.0 International license .

at the discretion of a vascular neurologist. EVT treatment decisions were guideline-based at the discretion of the treating vascular neurologist and neurointerventionalist. Thrombolysis in cerebral infarction (TICl) scores were determined by a neurointerventionalist using the modified scale: $2 a$ partial filling $<50 \%, 2 b$ partial filling $\geq 50 \%$, 3 complete perfusion. ${ }^{3}$ Adequate reperfusion was defined as $\mathrm{TICl} 2 \mathrm{~b}-3 .{ }^{31}$ Symptomatic intracerebral hemorrhage $(\mathrm{SICH})$ was defined as any $\mathrm{PH} 1$ or $\mathrm{PH} 2$ by ECASS criteria associated with new symptoms during the hospitalization. ${ }^{32}$ 90-day modified Rankin Scale (mRS) was obtained by telephone call or follow-up clinic visit. ${ }^{33,34}$ Good functional outcome was defined as 90 -day $\mathrm{mRS} \leq 2 .{ }^{35}$

Median and interquartile range (IQR) were reported for continuous nonparametric variables. Percent and count were reported for categorical variables. Differences among three groups of nonparametric continuous variables were assessed using the Kruskal Wallis test. Associations with good functional outcome were assessed by logistic regression. Variables of interest were selected a priori for their possible relevance to good functional outcome. Distributions were assumed nonparametric based on the Kolmogorov-Smirnov and Shapiro-Wilk tests. Two-tailed $P$ values $<0.05$ were considered statistically significant. Analyses were performed with Prism version 6.01 (GraphPad) and SPSS version 23.0 (IBM Corp).

\section{References:}

1. Regenhardt, R. W. et al. Blood pressure and penumbral sustenance in stroke from large vessel occlusion. Front. Neurol. 8, 317 (2017).

2. Goyal, M. et al. Endovascular thrombectomy after large-vessel ischaemic stroke: A meta-analysis of individual patient data from five randomised trials. Lancet 387, 1723-1731 (2016).

3. Nogueira, R. G. et al. Thrombectomy 6 to 24 Hours after Stroke with a Mismatch between Deficit and Infarct. N. Engl. J. Med. 378, 11-21 (2018).

4. Albers, G. W. et al. Thrombectomy for Stroke at 6 to 16 Hours with Selection by Perfusion Imaging. N. Engl. J. Med. 378, 708-718 (2018).

5. Regenhardt, R. W., Takase, H., Lo, E. H. \& Lin, D. J. Translating concepts of neural repair after stroke: Structural and functional targets for recovery. Restor. Neurol. Neurosci. 38, 67-92 (2020).

6. $\mathrm{Yu}, \mathrm{A}$. T. et al. CTA Protocols in a Telestroke Network Improve Efficiency for Both Spoke and Hub Hospitals. Am. J. Neuroradiol. (2021). doi:10.3174/ajnr.A6950

7. Regenhardt, R. W. et al. Opportunities for intervention: stroke treatments, disability and mortality in urban Tanzania. Int. J. Qual. Heal. Care 31, 385-392 (2019).

8. Leslie-Mazwi, T. M. et al. Endovascular stroke treatment outcomes after patient selection based on magnetic resonance imaging and clinical criteria. JAMA Neurol. 73, 43-49 (2016).

9. Regenhardt, R. W. et al. Delays in the Air or Ground Transfer of Patients for Endovascular Thrombectomy. Stroke 49, 1419-1425 (2018).

10. Sarraj, A. et al. Early Infarct Growth Rate Correlation With Endovascular Thrombectomy Clinical Outcomes. Stroke 52, 57-69 (2021).

11. Souza, L. C. S. et al. Malignant CTA collateral profile is highly specific for large admission DWI infarct core and poor outcome in acute stroke. Am. J. Neuroradiol. 33, 1331-1336 (2012).

12. Regenhardt, R. W., González, R. G., He, J., Lev, M. H. \& Singhal, A. B. Symmetric CTA Collaterals Identify Patients with Slow-progressing Stroke Likely to Benefit from Late Thrombectomy. Radiology (2021). doi:10.1148/radiol.2021210455

13. Consoli, A. et al. CT perfusion and angiographic assessment of pial collateral reperfusion in acute ischemic stroke: the CAPRI study. J. Neurointerv. Surg. 8, 1211-1216 (2016).

14. Al-Dasuqi, K. et al. Effects of Collateral Status on Infarct Distribution following Endovascular Therapy in Large Vessel Occlusion Stroke. Stroke 193-202 (2020). doi:10.1161/STROKEAHA.120.029892

15. Saarinen, J. T., Rusanen, H. \& Sillanpää, N. Collateral Score Complements Clot Location in Predicting the Outcome of Intravenous Thrombolysis. Am. J. Neuroradiol. 35, 1892-1896 (2014).

16. Fanou, E. M. et al. Effect of Collaterals on Clinical Presentation, Baseline Imaging, Complications, 
medRxiv preprint doi: https://doi.org/10.1101/2022.01.29.22270093; this version posted February 7, 2022. The copyright holder for this preprint (which was not certified by peer review) is the author/funder, who has granted medRxiv a license to display the preprint in perpetuity. It is made available under a CC-BY-NC-ND 4.0 International license .

and Outcome in Acute Stroke. AJNR. Am. J. Neuroradiol. 36, 2285-2291 (2015).

17. De Havenon, A. et al. Results from DEFUSE 3: Good collaterals are associated with reduced ischemic core growth but not neurologic outcome. Stroke 50, 632-638 (2019).

18. Regenhardt, R. W. et al. White Matter Acute Infarct Volume After Thrombectomy for Anterior Circulation Large Vessel Occlusion Stroke is Associated with Long Term Outcomes. J. Stroke Cerebrovasc. Dis. 30, 105567 (2021).

19. Regenhardt, R. W. et al. Infarct Growth despite Endovascular Thrombectomy Recanalization in Large Vessel Occlusive Stroke. J. Neuroimaging 31, 155-164 (2020).

20. Takase, H. \& Regenhardt, R. Motor tract reorganization after acute central nervous system injury: A translational perspective. Neural Regeneration Research 16, 1144-1149 (2021).

21. Ma, J. et al. Prevention of the collapse of pial collaterals by remote ischemic perconditioning during acute ischemic stroke. J. Cereb. Blood Flow Metab. 37, 3001-3014 (2017).

22. Lin, L. et al. Association of Collateral Status and Ischemic Core Growth in Patients With Acute Ischemic Stroke. Neurology 96, e161-e170 (2021).

23. Nogueira, R. G. et al. Stroke Imaging Selection Modality and Endovascular Therapy Outcomes in the Early and Extended Time Windows. Stroke 52, (2021).

24. Zachrison, K. S. et al. Frequency of early rapid improvement in stroke severity during interfacility transfer. Neurol. Clin. Pract. 9, 373-380 (2019).

25. Regenhardt, R. W. et al. 'Drip-and-ship' intravenous thrombolysis and outcomes for large vessel occlusion thrombectomy candidates in a hub-and-spoke telestroke model. J. Neurointerv. Surg. (2021). doi:10.1136/neurintsurg-2021-017819

26. Boulouis, G. et al. Immediate Vascular Imaging Needed for Efficient Triage of Patients With Acute Ischemic Stroke Initially Admitted to Nonthrombectomy Centers. Stroke (2017). doi:10.1161/STROKEAHA.117.017607

27. Regenhardt, R. W. et al. Radiomic signature of DWI-FLAIR mismatch in large vessel occlusion stroke. J. Neuroimaging (2021). doi:10.1111/jon.12928

28. Nolan, N. M. et al. Treatment Approaches and Outcomes for Acute Anterior Circulation Stroke Patients with Tandem Lesions. J. Stroke Cerebrovasc. Dis. 30, 105478 (2021).

29. Collaborators, N. A. S. C. E. T. et al. Beneficial effect of carotid endarterectomy in symptomatic patients with high-grade carotid stenosis. N. Engl. J. Med. 325, 445-453 (1991).

30. Regenhardt, R. W. et al. Sex-specific differences in presentations and determinants of outcomes after endovascular thrombectomy for large vessel occlusion stroke. J. Neurol. (2021). doi:10.1007/s00415-021-10628-0

31. Goyal, M. et al. Endovascular thrombectomy after large-vessel ischaemic stroke: A meta-analysis of individual patient data from five randomised trials. Lancet 387, 1723-1731 (2016).

32. Hacke, W. et al. Intravenous thrombolysis with recombinant tissue plasminogen activator for acute hemispheric stroke. The European Cooperative Acute Stroke Study (ECASS). JAMA 274, 1017-1025 (1995).

33. van Swieten, J. C., Koudstaal, P. J., Visser, M. C., Schouten, H. J. \& van Gijn, J. Interobserver agreement for the assessment of handicap in stroke patients. Stroke 19, 604-7 (1988).

34. Young, M. J., Regenhardt, R. W., Leslie-Mazwi, T. M. \& Stein, M. A. Disabling stroke in persons already with a disability: Ethical dimensions and directives. Neurology 94, 306-310 (2020).

35. Regenhardt, R. W. et al. Toward a more inclusive paradigm: thrombectomy for stroke patients with pre-existing disabilities. J. Neurointerv. Surg. (2020). doi:10.1136/neurintsurg-2020-016783

\section{Acknowledgments:}

Ms. Joyce A McIntrye maintained the local stroke database. 
medRxiv preprint doi: https://doi.org/10.1101/2022.01.29.22270093; this version posted February 7, 2022. The copyright holder for this preprint (which was not certified by peer review) is the author/funder, who has granted medRxiv a license to display the preprint in perpetuity.

\section{Author Contributions:}

RWR, MHL, ABS, and RGG conceived the idea. MHL and RGG assessed collateral patters. ABS led clinical data collection. RWR, JDR, CJS, ABP performed thrombectomies. RWR, JH, and RGG led data analysis and interpretation. RWR prepared the first draft of the manuscript. All authors read, provided significant edits, and approved the final manuscript.

\section{Data Availability:}

The data supporting these findings will be made available upon reasonable request and pending approval of the local institutional review board.

\section{Competing Interests:}

RWR (R25NS065743), RGG (U01EB025153), and ABS (U24NS107243, U01NS095869, R01NS105875, R01NS051412, P50NS051343) have been supported by the National Institutes of Health, National Institute of Neurological Disorders and Stroke. MHL has been a consultant for Takeda Pharm and GE Healthcare, and has received an institutional research grant from GE Healthcare. ABP has been a consultant for Penumbra, Medtronic, and Microvention. There are no other relevant competing interests. 